\title{
Ultrastructural and molecular analyses of homozygous-viable Drosophila melanogaster muscle mutants indicate there is a complex pattern of myosin heavy-chain isoform distribution
}

\author{
Patrick T. O'Donnell, Venetia L. Collier, Kaname Mogami, ${ }^{1}$ and Sanford I. Bernstein ${ }^{2}$ \\ Biology Department and Molecular Biology Institute, San Diego State University, San Diego, California 92182 USA; \\ 'Department of Physics, Faculty of Science, University of Tokyo, Hongo, Bunkyo, Tokyo 113, Japan
}

\begin{abstract}
We describe the ultrastructural and initial molecular characterization of four homozygous-viable, dominantflightless mutants of Drosophila melanogaster. Genetic mapping indicates that these mutations are inseparable from the known muscle myosin heavy-chain (MHC) allele $\boldsymbol{M h} \boldsymbol{c}^{1}$, and each mutation results in a muscle-specific reduction in MHC protein accumulation. The indirect flight muscles (IFMs) of each of these homozygous mutants fail to accumulate MHC, lack thick filaments, and do not display normal cylindrical myofibrils. As opposed to the null phenotype observed in the IFM, normal amounts of MHC accumulate in the leg muscles of three of these mutants, whereas the fourth mutant shows a $45 \%$ reduction in leg muscle MHC. The ultrastructure of the tergal depressor of the trochanter muscle (TDT, or jump muscle) is normal in one mutant, completely lacks thick filaments in a second mutant, and displays a reduction of thick filaments in two mutants. The thick filament reduction in this latter class of mutants is limited to the four smaller anterior cells of the TDT, indicating that the TDT is a mixed fiber-type muscle. Because all isoforms of muscle MHC are encoded by alternative splicing of transcripts from a single gene, our results suggest that there is a complex pattern of MHC isoform accumulation in Drosophila. The phenotypes of the homozygous-viable mutants provide evidence for the differential localization of MHC isoforms in different muscles, within the same muscle, and even within a single muscle cell. The mutant characteristics also suggest that the use of some alternative exons is shared among the IFM, TDT, and additional muscles whereas the use of others is unique to the IFM.
\end{abstract}

[Key Words: Drosophila; muscle mutants; myosin heavy chain; alternative RNA splicing]

Received February 9, 1989; revised version accepted May 31, 1989.

In both vertebrates and invertebrates, muscle myosin heavy-chain (MHC) isoforms are synthesized in different muscles and/or at different stages of development (for review, see Swynghedauw 1986; Emerson and Bernstein 1987). Sequence differences among the isoforms are thought to impart heterogeneity in properties important to the muscle-specific function of the contractile apparatus such as ATPase activity, actin, or myosin lightchain binding and mode of assembly into thick filaments. At present, it is not understood how sequence differences among $\mathrm{MHC}$ isoforms affect the function of domains within this protein. MHC isoform differences have been most commonly mapped by partial digestion of the proteins followed by gel electrophoresis (Whalen et al. 1981), by using MHC isoform-specific antibodies (Silberstein et al. 1986) and in some cases, by the com-

${ }^{2}$ Corresponding author. parison of DNA sequences (Mahdavi et al. 1982; Karn et al. 1983; Umeda et al. 1983; Mahdavi et al. 1984). These approaches have proved cumbersome, as a result of the large size of MHC genes and the proteins they encode and because $\mathrm{MHC}$ isoform diversity is usually the product of large multigene families (Swynghedauw 1986; Emerson and Bernstein 1987).

Unlike all other organisms characterized to date, Drosophila melanogaster possesses a single muscle MHC gene (Bernstein et al. 1983; Rozek and Davidson 1983). Alternative splicing of $\mathrm{MHC}$ transcripts results in the production of transcripts encoding different $\mathrm{MHC}$ isoforms (Bernstein et al. 1986; Rozek and Davidson 1986; Wassenberg et al. 1987; George et al. 1989; Hess et al. 1989). Analysis of the alternative exons of the Drosophila MHC gene and the muscle-specific splicing pattern of MHC transcripts will prove valuable in defining protein domains that are critical to the differential function of MHC protein isoforms. 
D. melanogaster is a useful organism in which to study muscle assembly, development, and function because physiological and molecular analyses can be aided by the relative ease of mutant isolation and manipulation. Mutations that affect muscle structure and function are isolated readily (Deak 1977; Koana and Hotta 1978; Mogami and Hotta 1981) because the function of the indirect flight muscle (IFM) and the jump muscle or tergal depressor of the trochanter muscle (TDT) are not essential to viability or fertility. We showed previously that two wild-type copies of the MHC gene are required for IFM and TDT function, whereas other muscles function adequately with a single copy (Mogami et al. 1986; O'Donnell and Bernstein 1988). This sensitivity of IFM and TDT function to gene dosage extends to other muscle contractile protein genes as well and has permitted the isolation of dominant flightless mutations in genes encoding actin and tropomyosin isoforms specific to the IFM (Karlik et al. 1984; Hiromi and Hotta 1985; Karlik and Fyrberg 1985).

Previously reported dominant flightless MHC mutations are homozygous-lethal during the embryonic or early larval stages, due to lesions that affect the function or accumulation of all muscle MHC isoforms (Mogami et al. 1986; O'Donnell and Bernstein 1988). In this paper we describe the ultrastructural and initial molecular analysis of a homozygous-viable class of MHC mutants. We show that four hypomorphic mutations affect only a restricted subset of muscles and that the mutations result in strikingly different phenotypes. Furthermore, our mutant analyses indicate that the TDT is a mixed fiber muscle with two cell types that may accumulate different MHC isoforms. In situ hybridization with an antisense $\mathrm{MHC}$ gene probe indicates that two of the mutations affect the accumulation of MHC transcripts in subsets of muscle, whereas the other two mutations probably result in the synthesis of unstable MHC isoforms within certain muscles. Our analysis of the homozygous-viable class of $\mathrm{MHC}$ mutations provides genetic evidence that there is a complex distribution of MHC isoforms in Drosophila muscles.

\section{Results}

\section{Genetic mapping of the homozygous-viable mutants}

We were interested in determining whether muscle MHC gene mutations could affect flight muscle function, yet not result in recessive lethality. To explore this possibility, several second chromosomal homozygousviable mutations were mapped relative to the known MHC mutation $M c^{1}$ (Mogami et al. 1986; O'Donnell and Bernstein 1988). Progeny of the cross between $b$ $M h c^{1} \mathrm{pr} / \mathrm{mutant}$ (females) and al b pr px sp (males) were scored for the number of recombinant fliers, as well as the number of recombinants between $b$ and $p r(b$ and $p r$ flank the MHC gene). The results for four of the mutants are shown in Table 1 . In no case for the mutants $M h c^{7}$, $M h c^{9}, M h c^{10}$, and $M h c^{11}$ was a recombinant flier recovered, suggesting that these four mutations are insepa- rable from the MHC locus (for the nomenclature of the MHC mutants, see Materials and methods). Because only half of the recombinants between the muscle mutations (those that fly) would be detected, the data indicate that the mutations are $<0.08-0.44$ map units from the MHC gene [this corresponds to $22-121 \mathrm{~kb}$ of DNA according to Kidd et al. (1983)]. Our results are consistent with data of Homyk and Emerson (1988), who found no recombinants between $M h c^{1}$ and $M h c^{7}$ among 12,875 progeny tested.

The genetic recombination data suggested that the homozygous-viable muscle mutations are within the MHC gene. We therefore examined whether the flightless phenotypes of the mutants could be rescued by a chromosomal duplication of the 35B3,4-36C11 region that includes the MHC gene at 36B. Homozygous mutant virgins were crossed to males carrying the duplication, and the progeny $\left(M \mathrm{Mc}^{+} / \mathrm{Mhc}^{+} /\right.$mutation) were tested for flight ability. In each case, the flightless phenotype of the mutant was rescued by the duplication. This suggests that the mutations are hypomorphic and do not result in the production of a neomorphic gene product that blocks muscle function in the presence of two wild-type alleles.

\section{Contractile protein accumulation in the homozygous-viable mutants}

Mogami and Hotta (1981) previously examined protein accumulation in thoraces of $M h c^{7}$ [formerly called Ifm(2)2] by two-dimensional gel electrophoresis. They found that two myosin light chains (spots 138, 185), as well as additional proteins (spots 158, 159), were missing and proteins 33 and 74 were reduced. To determine whether mutations $M h c^{9}, M h c^{10}$, and $M h c^{11}$ also affect the accumulation of myofibrillar proteins, we analyzed thoracic homogenates by two-dimensional gel electrophoresis. We found that the same spots are missing or reduced in the thoraces of these mutants as in the thoraces of $M h c^{7}$ (data not shown).

The absence of myosin light chains in these mutants is consistent with a defect in a thick filament protein that results in the turnover of other thick filament-associated proteins, due to lack of thick filament assembly [for a discussion of pleiotropic effects of contractile protein gene mutations, see Mogami and Hotta (1981)]. The failure to accumulate known thick filament proteins, in conjunction with the genetic recombination and mutant rescue data, strongly suggested that the mutations are defects within the $\mathrm{MHC}$ gene that result in the underproduction of MHC protein. Because two-dimensional gels give poor resolution of $\mathrm{MHC}$, we used one-dimensional gel electrophoresis to compare MHC protein accumulation in wild-type and mutant thoraces and in wild-type and mutant leg tissues (Fig. 1; Table 1). All of the mutants showed a $>95 \%$ reduction in $\mathrm{MHC}$ accumulation in the upper thorax (which is composed mainly of the IFM and TDT). However, unlike the homozygous-lethal mutants that affect MHC accumulation in all muscle types (Mogami et al. 1986; O'Donnell 
Table 1. Characteristics of the homozygous-viable dominant-flightless MHC mutations

\begin{tabular}{|c|c|c|c|c|c|c|c|c|c|}
\hline \multirow[b]{4}{*}{ Mutant } & \multirow{4}{*}{$\begin{array}{l}\text { Recomb. with } \\
M h c^{1 / \text { recomb. }} \\
\text { between } p \text { and } b r / \\
\text { total progeny tested }\end{array}$} & \multirow{2}{*}{\multicolumn{2}{|c|}{$\begin{array}{c}\text { Protein } \\
\text { accumulation } \\
|\%| \\
\end{array}$}} & \multirow{4}{*}{$\begin{array}{l}\text { Jump muscle } \\
\text { function relative } \\
\text { to wild type } \\
(\%)\end{array}$} & \multirow{2}{*}{\multicolumn{3}{|c|}{$\begin{array}{r}\text { Muscle structure } \\
\text { TDT }\end{array}$}} & \multirow{3}{*}{\multicolumn{2}{|c|}{ MHC RNA }} \\
\hline & & & & & & & & & \\
\hline & & upper & & & \multirow[b]{2}{*}{ IFM } & \multirow{2}{*}{$\begin{array}{l}\text { small } \\
\text { cells }\end{array}$} & \multirow{2}{*}{$\begin{array}{l}\text { large } \\
\text { cells }\end{array}$} & & \\
\hline & & thorax & leg & & & & & IFM & TDT \\
\hline$M h c^{7}$ & $0 / 98 / 2521$ & 3 & 115 & 33 & - & \pm & + & - & + \\
\hline$M h c^{9}$ & $0 / 19 / 631$ & 4 & 105 & 59 & - & \pm & + & + & + \\
\hline$M h c^{10}$ & $0 / 70 / 1526$ & 0 & 55 & 0 & - & - & - & - & - \\
\hline$M h c^{11}$ & $0 / 7 / 454$ & 3 & 105 & 98 & - & + & + & + & + \\
\hline
\end{tabular}

The mutations were genetically mapped relative to the known MHC mutation $M h c^{1}$. Progeny of the cross between $b \mathrm{Mhc} \mathrm{c}^{1} \mathrm{pr} / \mathrm{mutant}$ females and $a l b$ pr px sp males were scored for the number of recombinant fliers and the number of recombinants between $b$ and $p r(b$ and $p r$ flank the MHC gene and are 6 map units apart). The total number of progeny tested is indicated also. MHC accumulation in the thorax and the legs of the mutants was measured by scanning densitometry of SDS-polyacrylamide gels. Levels of protein were compared to those of wild type, as indicated in Materials and methods. Jump muscle function was calculated relative to wild type by measuring the average distance that 30 flies jumped (or fell) from a raised petri dish (see Materials and methods). Wild-type flies jumped $9.6 \mathrm{~mm}$, on average, and this was taken to indicate $100 \%$ jump muscle function. $M \mathrm{Mc}^{10}$ flies exhibit no vertical jumping ability; therefore, their average distance of $4.7 \mathrm{~mm}$ indicates $0 \%$ jump muscle function. The structure of the IFM and the small and large cells of the TDT in wild type and the mutants was characterized by transmission electron microscopy (see Figs. 2 and 4). Muscle structure in the mutants: $(+1$ Thick filaments and myofibrils are present; $( \pm)$ some thick filaments and myofibrils are present but are abnormal in shape; $1-\mid$ thick filaments and myofibrils are absent. MHC RNA accumulation was determined by in situ hybridization (see Fig. 5). (+) Normal MHC RNA accumulation; (-) an absence of MHC RNA in the IFM or TDT.

and Bernstein 1988), leg muscles of $M h c^{7}, M h c^{9}$, and $M h c^{11}$ show no reduction in MHC accumulation. Interestingly, MHC accumulation in the leg muscles of $M h c^{10}$ is reduced $45 \%$ compared to that of wild type. Thus, all of the mutations have a similar effect on MHC accumulation in the upper thorax, whereas $M h c^{10}$ affects accumulation of MHC in leg muscles also.

\section{Structure of the IFM in wild type and mutants}

The MHC protein accumulation data indicated that the hypomorphic homozygous-viable mutations affect only a limited set of muscles, which include the IFM. To investigate this at the ultrastructural level, we used transmission electron microscopy to examine the structure of both wild-type and mutant IFM. Figure 2 , $a$ and $b$, shows transverse sections of the IFM of wild-type and the homozygous-viable mutant $M h c^{10}$. In the wild type, myofibrils are cylindrical, with an average diameter of $1.5 \mu \mathrm{m}$. Interdigitating thick and thin filaments form a double hexagonal lattice, with thin filaments occupying positions midway between each adjacent pair of thick filaments. One striking feature of the lattice is its precise regularity, with each thick filament surrounded by six thin filaments. Thick filaments of the IFM have a hollow core. Large mitochondria fill the space between the myofibrils, and glycogen granules are abundant. A very striking phenotype is seen in the IFM of the mutant $M h c^{10}$. There is a complete absence of cylindrical myofibrils; instead the muscle is composed of a nearly continuous sheet of myofilaments. No thick filaments with a hollow core structure are present. Glycogen granules and mitochondria appear similar to wild type. Transverse sections of the IFM from the mutants $M h c^{7}, M h c^{9}$, and $M h c^{11}$ indicate that their phenotypes are similar to $M h c^{10}$ (data not shown).

Figure 2, c and d, shows longitudinal sections of the IFM of wild-type and the mutant $M h c^{10}$. In the wild type, sarcomere length is $\sim 3 \mu \mathrm{m}$. The M-band is clearly demarcated by the presence of a well-defined band of
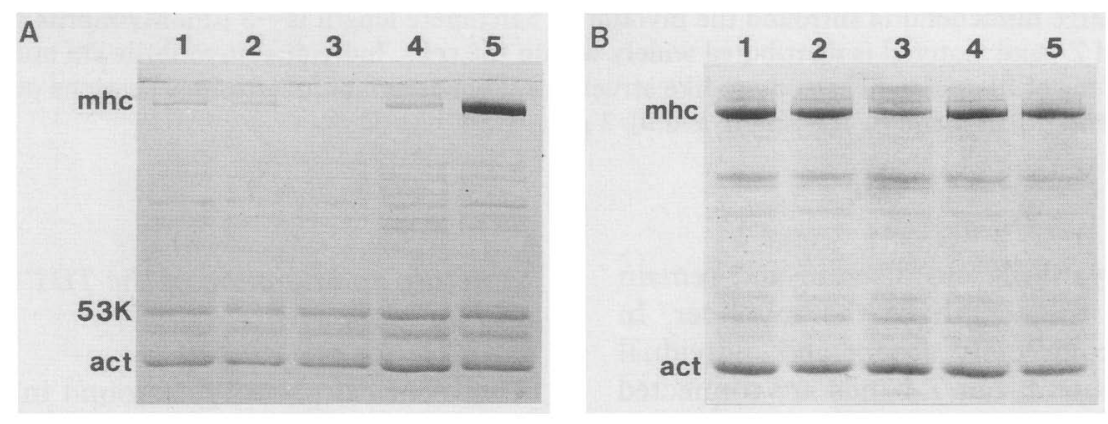

Figure 1. MHC protein accumulation in the upper thoraces $(A)$ and legs $(B)$ of the homozygous mutants and wild type. The location of MHC and two control proteins (actin and 53K) are indicated. (Lane 1) $M h c^{7}$; (lane 2) $M h c^{9}$; (lane 3) $M h c^{10}$; (lane 4) $M h c^{11}$; (lane 5) Canton S. 
O'Donnell et al.
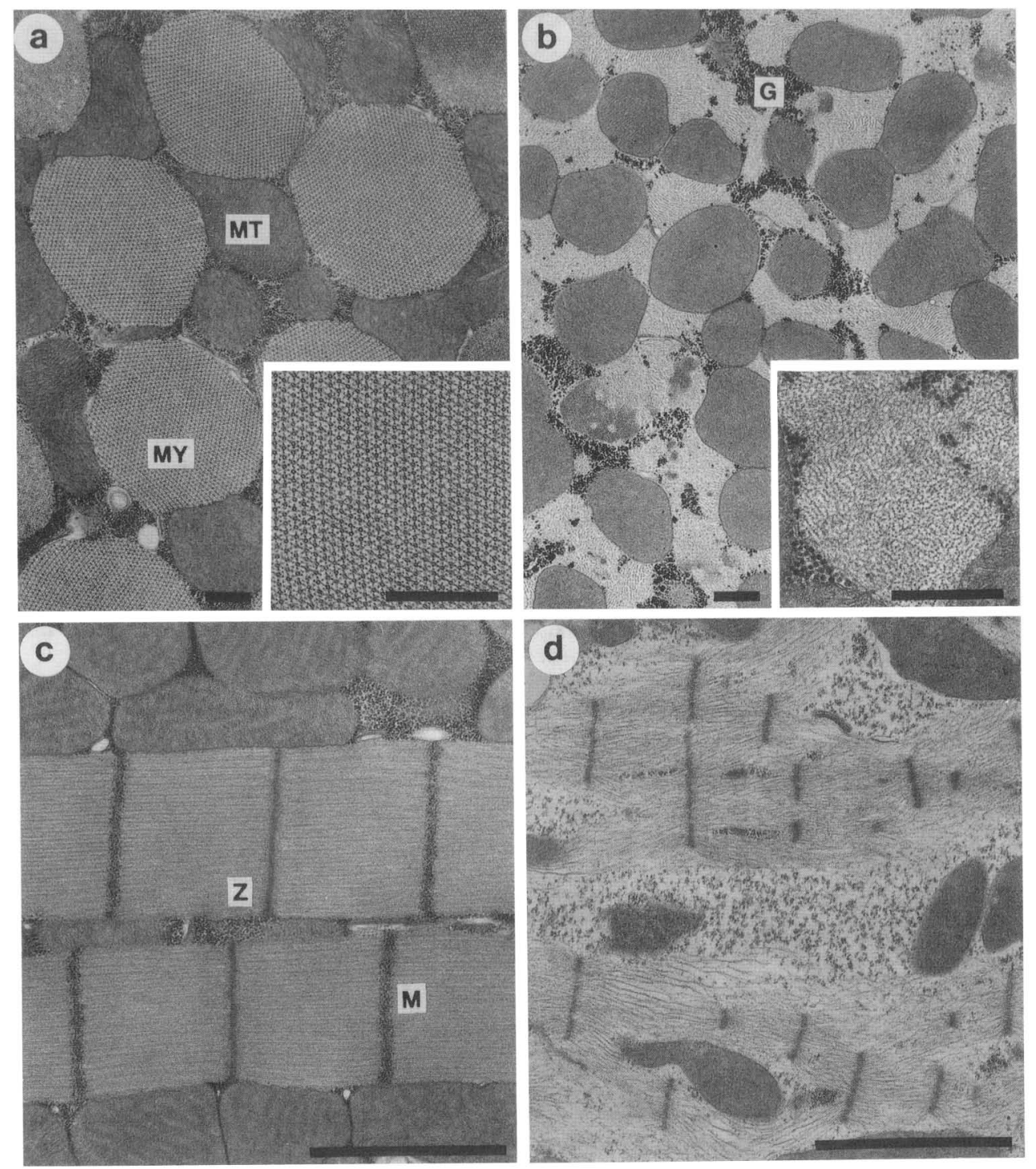

Figure 2. Transverse sections of the IFM from wild type $(a)$ and the mutant $M h c^{10}(b)$. Wild-type IFM contains many cylindrical myofibrils (MY) that are surrounded by large mitochondria (MT) and glycogen granules (G). The myofibrils display a highly ordered double hexagonal array of thick and thin filaments. Myofibrils have an average diameter of $1.5 \mu \mathrm{m}$. Thick filaments appear to have a hollow core. Myofibrils of the mutant $M h c^{10}$ show a complete absence of wild-type thick filaments and cylindrical myofibrils. The remaining myofilaments form a nearly continuous sheet, interrupted only by mitochondria, glycogen granules, and sections of sarcoplasmic reticulum. Phenotypes of transverse sections of the other mutants are similar to that seen for $M h c^{10}$. Longitudinal sections of the IFM from wild type $(c)$ and the mutant $M h c^{10}(d)$. The longitudinal section of wild type illustrates the highly ordered structure of IFM sarcomeres. Z-bands $(Z)$ and $M$-bands $(M)$ are well defined. Wild-type myofibrils are discrete and remain this way through the length of the myofiber. Large mitochondria surround the myofibrils. Sarcomere length is $\sim 3 \mu \mathrm{m}$. Myofibrils from the mutants completely lack M-bands, and Z-band material is distributed widely within the cells. Individual myofibrils are not apparent, but Z-bands are connected by collections of filaments in sarcomere-like structures. Phenotypes of longitudinal sections of the other mutants are similar to that seen for $M h c^{10}$. Bar $(a$ and $b), 0.5 \mu \mathrm{m} ;(c$ and $d), 2 \mu \mathrm{m}$.

glycogen granules. Myofibrils are discrete and remain this way throughout the length of the myofiber. In $M h c^{10}, \mathrm{M}$-bands are completely absent and individual myofibrils are not apparent, but Z-bands are connected by collections of filaments in 'sarcomere-like' structures. Longitudinal sections of the mutants $M h c^{7}, M h c^{9}$ and $M h c^{11}$ indicate their phenotypes are similar to $M h c^{10}$ (data not shown).

\section{Structure and function of the TDT in wild type} and mutants

The identical phenotypes found in the IFM of the four homozygous-viable mutants suggested that the mutations represent similar molecular lesions within the MHC gene. To explore this possibility we examined the effect of the mutations on TDT structure. Figure 3 


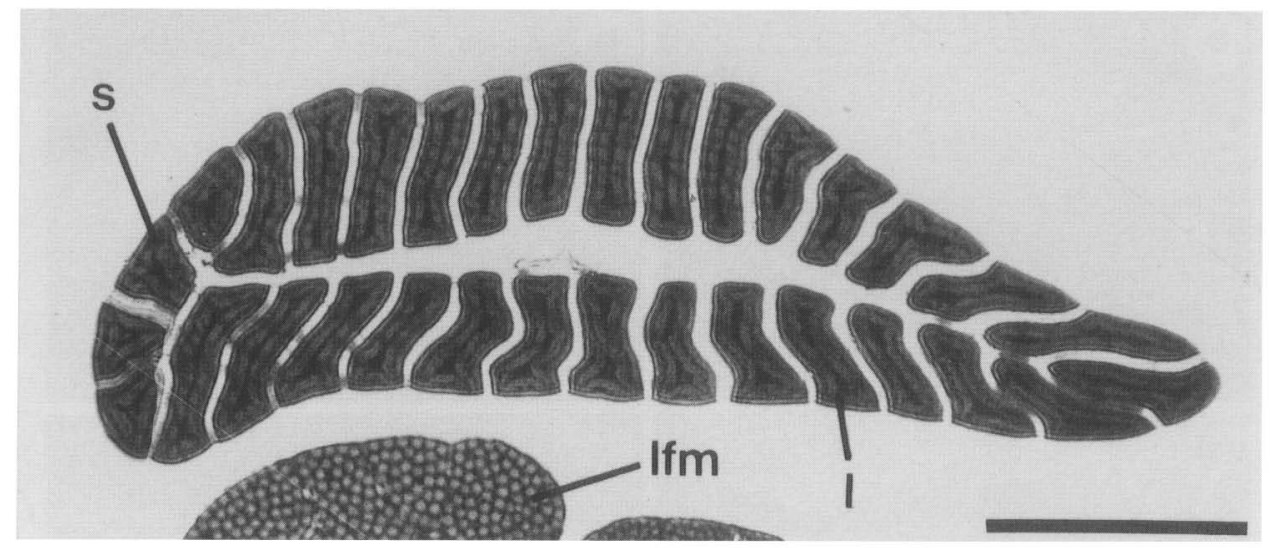

Figure 3. Structure of the TDT in transverse section under low magnification. Thoraces embedded in Spurr's medium were sectioned and mounted on glass slides. Sections were stained with $0.1 \%$ toluidine blue, $1 \%$ sodium tetraborate for one minute and destained with distilled water prior to examination by light microscopy. The TDT is composed of 32 cells situated in an oval pattern. Four cells (s) at the anterior end of the muscle are smaller in size than the remaining 28 cells (l). IFM myofibers (Ifm) are situated next to the TDT. Bar, $40 \mu \mathrm{m}$.

shows this muscle in transverse section under low magnification. The TDT is composed of 32 muscle cells situated in an oval pattern. The 4 anterior cells are smaller in size than the remaining 28 cells. Figure 4 , a and b, shows the ultrastructure of the large and small cells of wild-type TDT. The structure of the myofilament lattice and the myofibril organization for both cell types are nearly identical. TDT cells contain large numbers of rectangular myofibrils that are delineated by an extensive system of sarcoplasmic reticulum. Mitochondria are relatively small and found infrequently. Each thick filament is surrounded by an average of $10-11$ thin filaments. Thick filaments, as in the IFM, possess hollow cores and are uniform in diameter, although the filament array does not have the same precise regularity as the double hexagonal lattice seen in the IFM. However, thick filaments do tend to be organized such that straight lines can be drawn through the center of a series of them. The only distinguishing characteristic of the small cells of the TDT is that the cross-sectional area of each myofibril is approximately half that of a large cell myofibril.

The structures of the TDT in the mutants $M \mathrm{Mc}^{7}$ and $M h c^{9}$ show similar abnormalities (Fig. $4 \mathrm{c}-\mathrm{f}$ ). The small TDT cells of $M h c^{7}$ and $M h c^{9}$ contain poorly organized rectangular myofibrils. Where myofibrils do form, their cross-sectional area is reduced due to a reduction in the number of thick filaments. This results in each thick filament being surrounded by an increased number of thin filaments. Interestingly, thick filaments are not uniform in diameter, and most lack the hollow core structure common in wild type. Thick filaments are not arranged in a wild-type array, as straight lines cannot be drawn through the center of a series of them. The large cells of the TDT in the mutants $M h c^{7}$ and $M h c^{9}$ appear normal. Thick filament size, shape, and number are similar to wild type. The filament lattice is normal, and myofibrils are delineated by an organized sarcoplasmic reticulum system. The effect of the $M h c^{7}$ and $M h c^{9} \mathrm{mu}-$ tations on TDT structure appears limited to the small cell type.

The structure of the TDT in $M h c^{10}$ is shown in Figure $4, \mathrm{~g}$ and $\mathrm{h}$. The phenotype of the small cells is abnormal, as rectangular myofibrils are completely absent, sarcoplasmic reticulum is scattered randomly throughout the cells and no thick filaments are visible. The phenotype of the large cells of the TDT in $M h^{10}$ is also abnormal and is identical to that seen in the small cells. Therefore, the mutant $M h c^{10}$ is different from the mutants $M h c^{7}$ and $M h c^{9}$ because both the small and large cells are affected.

$M h c^{11}$ is unique in that the structures of both the large and small cells of the TDT (Fig. $4 \mathrm{i}, \mathrm{j}$ ) are normal. The rectangular myofibrils and myofilament lattice resemble those of wild type.

We examined the function of the TDT in each of these mutants and found a direct correlation of jumping ability with the presence of structurally normal jump muscle (Table 1). Although $M h c^{11}$ mutants jump at levels comparable to wild type $(98 \%), M h c^{7}$ and $M h c^{9}$ jumped only $33 \%$ and $59 \%$ as well. $M$ h $c^{10}$ mutants are unable to jump.

\section{MHC RNA accumulation in muscles of the mutants}

SDS-polyacrylamide gel electrophoresis and electron microscopic analysis indicated that MHC and thick filament accumulation is reduced or eliminated in some thoracic muscles of the homozygous-viable mutants. This MHC-null phenotype could result from either an absence of MHC transcripts or the production of an unstable MHC isoform within a subset of muscles. In situ hybridization was employed to differentiate between these possibilities. Labeled sense and antisense RNA probes containing exons 4,5 , and 6 (exons common to all MHC transcripts) were hybridized to cryosections of late-stage pupae to assay the accumulation of MHC transcripts in developing adult muscles. 

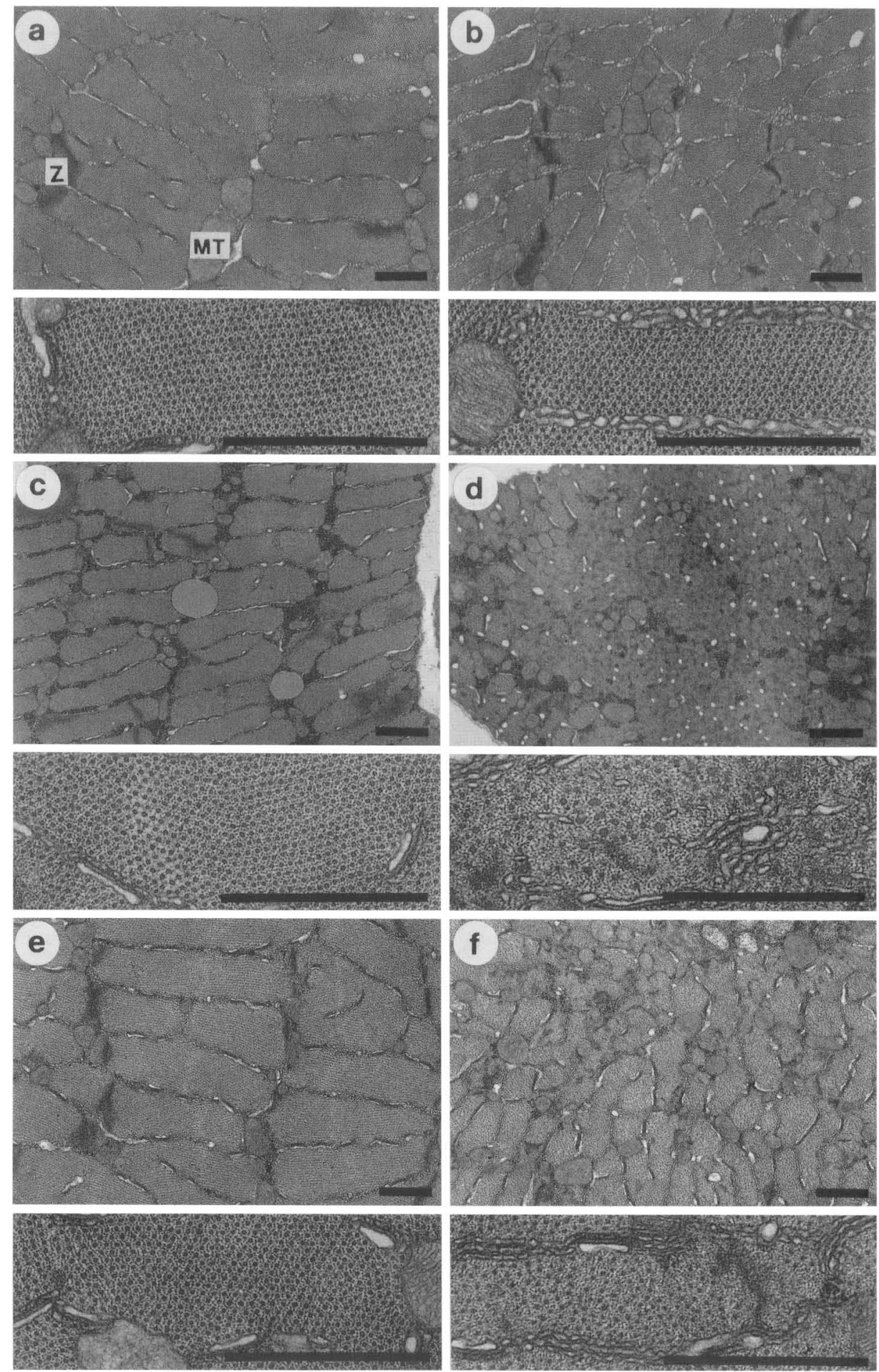

Figure 4. (See facing page for legend.)

Figure 5a shows a bright-field image of a parasagittal section of a wild-type pupa that has been hybridized to the sense MHC probe. As expected, silver grains are absent from the entire section. Figure $5 b$ shows a section of a wild-type pupa that has been hybridized to the antisense MHC probe. Silver grains appear over all muscle tissue and are especially concentrated over the IFM, the leg muscles, and the proboscis muscles. There is an absence of silver grains over most of the abdomen, which contains relatively little muscle tissue. Figure 5, e and g, shows parasagittal sections from the mutants $M h c^{9}$ and $M h c^{11}$, respectively. Significantly, the IFMs of both mutants possess distributions and concentrations of silver grains that are similar to wild type. The pattern of silver 

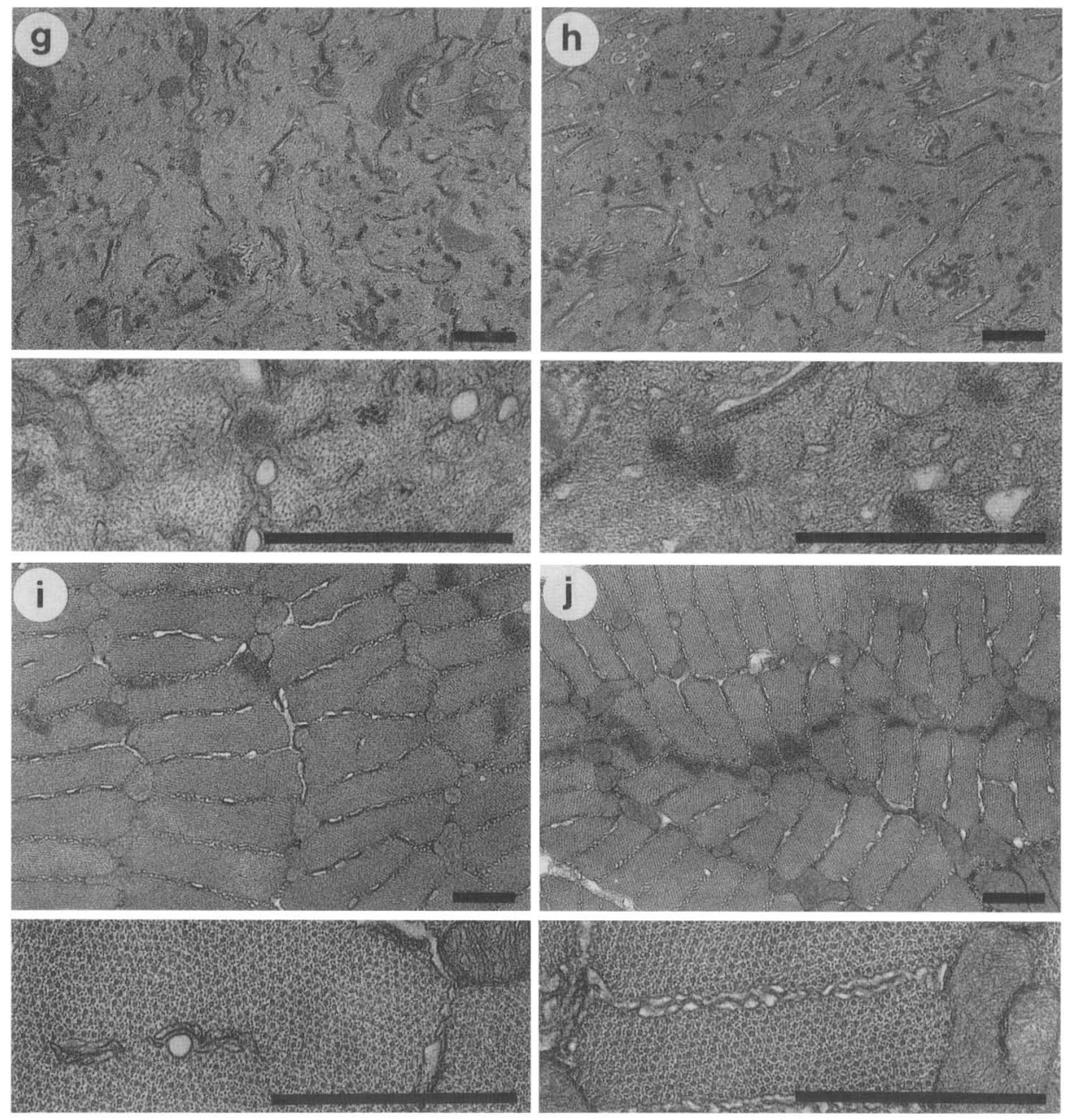

Figure 4. Ultrastructure of the TDT in wild type $(a$ and $b)$ and mutants $(c-i)$. The large cells $(a)$ and small cells $(b)$ of wild-type TDT. The structure of the myofilament lattice and the myofibril organization for both cell types are nearly identical. Each cell type contains large numbers of rectangular myofibrils that are delineated by an extensive system of sarcoplasmic reticulum. Mitochondria (MT) are relatively small, and infrequently distributed. $Z$ bands $(Z)$ are visible. Each thick filament is surrounded by an average of $10-11$ thin filaments. Thick filaments possess a hollow core, are uniform in diameter, and tend to be organized such that a straight line can be drawn through the center of a series of them. The only distinguishing characteristic of the small cells is that the cross-sectional area of the individual myofibrils is approximately half that of the larger cells. $(c-f)$ Structure of the TDT in $M h c^{7}$ and $M h c^{9}$. The phenotypes in the TDT of these mutants appear to be similar. The small cells of $M h c^{7}(d)$ and $M h c^{9}(f)$ are clearly abnormal, as the rectangular myofibrils are poorly organized. Where myofibrils do form, their cross-sectional area is reduced, apparently a result of a reduction in the number of thick filaments. This results in each thick filament being surrounded by an increased number of thin filaments. Thick filaments are not uniform in diameter, lack the normal hollow core structure, and are no longer arranged in an array such that a straight line can be drawn through the center of a series of them. The structure of the large cells in $M h c^{7}(c)$ and $M h c^{9}(e)$ appears similar to that of wild type. ( $g$ and $h$ ) Structure of the TDT in $M h c^{10}$. The ultrastructure of the small cells of $M h c^{10}(h)$ is abnormal. Rectangular myofibrils are absent completely and sarcoplasmic reticulum is scattered randomly throughout the small cells. No thick filaments are present. The structure of the large cells $(g)$ is abnormal also. The phenotype appears identical to that found in the small cells of $M h c^{10}$, as rectangular myofibrils and thick filaments are absent and sarcoplasmic reticulum is scattered within the cells. (i and i) Structure of the TDT in $M h c^{11}$. Both small cells $(j)$ and large cells $(i)$ appear similar to that of wild type. Bar, $0.75 \mu \mathrm{m}$.

grains over other muscle tissue also is similar to wild type. These in situ hybridization results indicate that stable MHC transcripts accumulate in the IFM of these two mutants, even though they fail to accumulate MHC and thick filaments.

Figure 5, c-d and $\mathrm{f}$, shows parasagittal sections of $M h c^{7}$ and $M h c^{10}$ pupae hybridized to the antisense MHC probe. A strikingly different pattern of hybridization is seen than that found in mutants $M h c^{9}$ and $M h c^{11}$. Although the proboscis muscles show wild-type concentrations of silver grains, the IFMs of $M h c^{7}$ and $M h c^{10}$ are devoid of silver grains. However, the hybridization patterns of the two mutants are not identical. Wild-type levels of silver grains are found over both the TDT (Fig. 5d) and leg muscles in $M h c^{7}$, whereas silver grains are absent from the TDT and the intensity of silver grains 

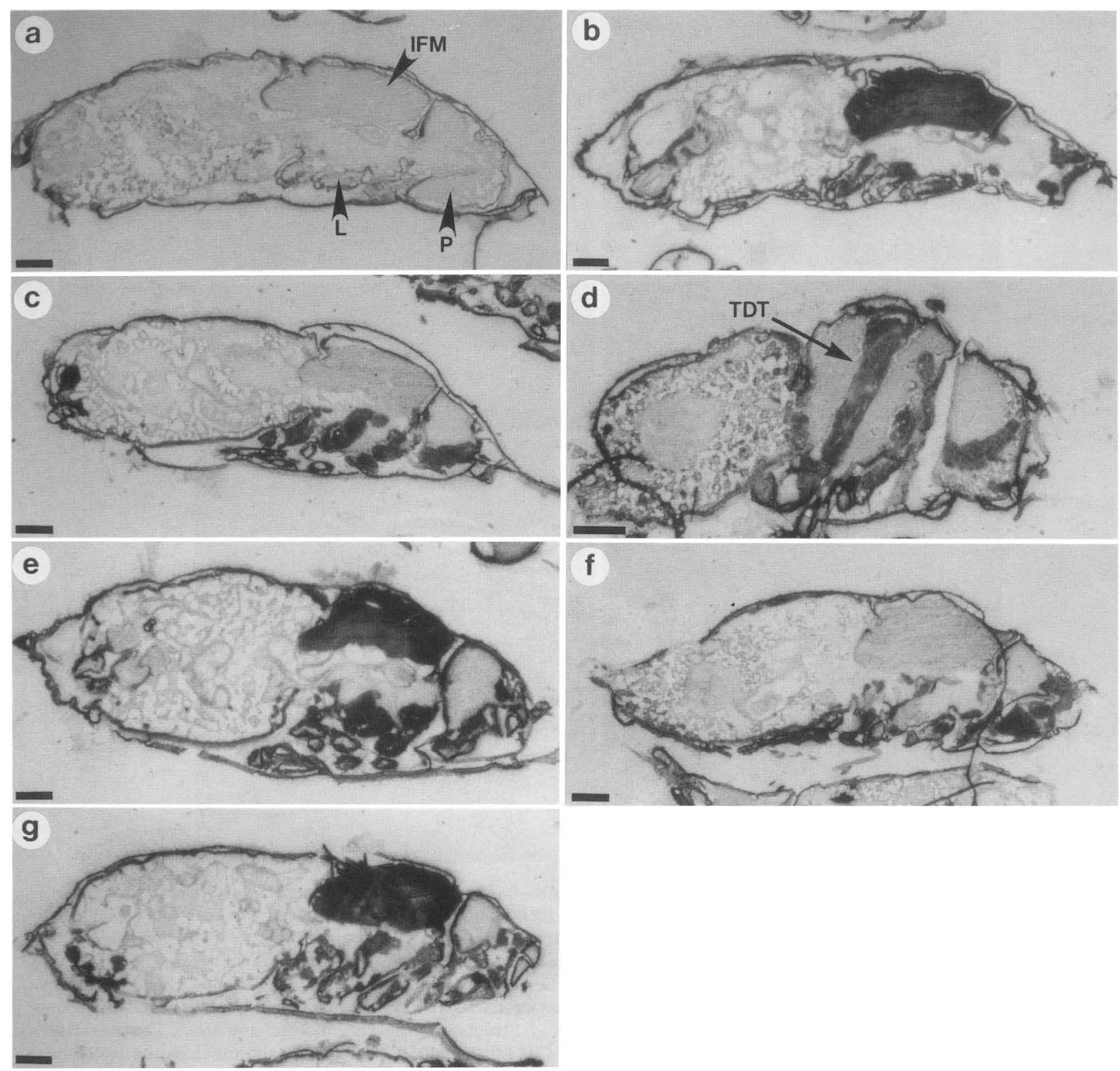

Figure 5. In situ hybridization to parasagittal cryosections of late-stage pupae using MHC sense or antisense RNA probes containing the constitutive exons 4,5 , and 6 . The antisense probe should hybridize to all MHC transcripts, whereas the control sense probe should exhibit no hybridization. Sections were stained with $5 \%$ Giemsa and photographed under bright-field microscopy. $(a)$ Wildtype pupa hybridized with the MHC sense probe. Silver grains are absent over the entire section, including the IFM, the proboscis muscles $(\mathrm{P})$, and the leg muscles $(\mathrm{L})$. A wild-type pupa $(b)$ probed with the MHC antisense probe shows strong concentrations of silver grains over each of these muscles, whereas most of the abdominal tissue remains unlabeled. In the mutant $M h c^{7}(c$ and $d)$ there is an absence of silver grains over the IFM, although there is normal transcript accumulation over the proboscis and leg muscles as well as the TDT $(d)$. In the mutant $M h c^{10}(f)$, as in the mutant $M h c^{7}$, there is an absence of silver grains over the IFM. Significantly, in $M h c^{10}$, MHC transcripts are also absent from the TDT (data not shown), and hybridization to the leg muscles appears weak. In the mutants $M h c^{9}(e)$ and $M h c^{11}(g)$, MHC RNA accumulation in all muscles is similar to that of wild type. Bar, $140 \mu \mathrm{m}$.

over the leg muscles appears reduced in $M h c^{10}$. These results indicate that the $M h c^{7}$ and $M h c^{10}$ mutations, unlike $M h c^{9}$ and $M h c^{11}$, affect MHC transcript accumulation within particular subsets of muscles.

\section{Discussion}

In this paper we describe four homozygous-viable flight- less mutations that have tissue-specific effects on muscle structure and function. Three lines of evidence indicate that these mutations are molecular defects within the Drosophila muscle MHC gene. First, we have shown that the homozygous-viable mutations are genetically tightly linked to the well-characterized MHC mutation $M h c^{1}$. The flightless phenotypes of each of the mutants can be rescued by a chromosomal duplication 
that includes the MHC gene. Second, ultrastructural and protein analyses of the homozygous-viable mutants indicate that each of the mutations reduces MHC accumulation and affects the accumulation and morphology of muscle thick filaments. The ultrastructural phenotypes are consistent with those of hypomorphic MHC mutants described previously in Caenorhabditis elegans (Epstein et al. 1974; Waterston et al. 1980) and D. melanogaster (O'Donnell and Bernstein 1988). Finally, our in situ hybridization results indicate that two of the homozygous-viable mutations prevent the accumulation of MHC transcripts within a subset of muscles. Chun and Falkenthal (1988) also have concluded recently that $M h c^{7}$ is a muscle MHC allele and that it has muscle-specific effects on MHC RNA and protein accumulation.

\section{Muscle diversity and the generation of $M H C$ isoforms in Drosophila}

Studies of Drosophila anatomy indicate that all muscles of the organism are striated and can be divided into two broad classes, consisting of fibrillar muscles and tubular muscles (Miller 1950). The IFM is the only fibrillar muscle, and its function is not necessary for viability. It occupies most of the thorax and functions to produce primary movements of the wings by changing the shape of the thorax. This muscle has evolved many special features (Shafiq 1963a,b; Smith 1963; Garamvolgyi 1965a,b; Peristianis and Gregory 1970; Cullen 1974; Crossley 1978) that allow it to produce high wing beat frequencies. The IFM also is unique because it displays asynchronous contraction, where a single burst from motor neurons causes activation that is maintained by rapid changes in length and tension, resulting from the mechanical properties of the muscle (Nachtigal and Wilson 1967; Pringle 1967; Thorson and White 1969; Tregear 1975|. The IFM is called fibrillar because the muscle cells contain large numbers of discrete cylindrical myofibrils that can be teased individually away during dissection. All other muscles of Drosophila are termed tubular in that the nuclei within each muscle cell line up along the periphery of the cell, giving it the appearance of a long tube when stained. This classification scheme underestimates the structural heterogeneity within the tubular muscles. The direct flight muscle, larval intersegmental muscle, leg muscle, and TDT all have been labeled tubular muscles, but examination of each of their ultrastructures indicates that they possess many unique characteristics (O'Donnell and Bernstein 1988, P. T. O'Donnell, unpubl.). Thus, the diversity seen in Drosophila muscle structure and function is similar to the complexity seen in vertebrates.

To generate MHC isoform diversity necessary for the observed physiological and ultrastructural differences in various Drosophila muscle types, the process of alternative RNA splicing is used. Sequencing of the single-copy MHC gene and analysis of cDNAs indicate that the gene contains two alternative copies of exon 3 , four copies of exon 7, three copies of exon 9, five copies of exon 11, two copies of exon 15, and a penultimate exon that is either included or excluded from mature MHC tran- scripts (Bernstein et al. 1986; Rozek and Davidson 1986; Wassenberg et al. 1987; George et al. 1989; Hess et al. 1989|. Analysis of the expression of the penultimate exon indicates that it is present in transcripts synthesized in the adult thorax and absent in most other muscles (Bernstein et al. 1986; Rozek and Davidson 1986), resulting in the muscle-specific localization of MHC isoforms with different carboxyl termini. We speculate that the carboxy-terminal sequence of MHC is critical to the assembly of myosin molecules into thick filaments (Kuczmarski and Spudich 1980; Kiehart and Pollard 1984; Kiehart et al. 1984; Dibb et al. 1985) and that differences in the sequence of the carboxyl termini may result in myosin molecules with alternative assembly properties. The tissue-specific expression of the other alternatively spliced exons within the MHC gene is poorly characterized. Like the penultimate exon, they probably encode domains that are important in the production of MHC isoforms possessing different biochemical properties. Alternative use of exons within a set may lead to significant changes in properties of myosin, such as ATPase activity, actin binding, and association of light chains. Heterogeneity among MHC isoforms probably makes an important contribution to the assembly of muscles that are structurally and functionally unique.

Phenotypes of the homozygous-viable mutants suggest defects in muscle-specific MHC isoforms

The phenotypes found in the homozygous-viable mutants are interpretable based on the complex structure of the single muscle-MHC gene. In the mutants $\mathrm{Mhc}^{7}$ and $M h c^{10}$, where MHC transcripts fail to accumulate in a subset of muscles, the mutations probably affect sequences important to the alternative processing (i.e., donor or acceptor splice sites, branchpoint site) of MHC transcripts, leading to transcript instability within the particular muscle types that use the alternative exons. Another explanation for the $M h c^{7}$ and $M h c^{10}$ mutations is that they represent DNA lesions in enhancer elements that lead to the elimination of MHC transcription in specific muscles. However, this is unlikely because preliminary data indicate that the $M h c^{7}$ and $M h c^{10} \mathrm{mu}-$ tations are associated with muscle-specific exons (W.A. Kronert, V.L. Collier, P.T. O'Donnell, K. Edwards, E.S. Roche, and S.I. Bernstein, in prep.). In mutants $M h c^{9}$ and $M h c^{11}$, where MHC transcripts accumulate to wildtype levels, the defects may be nonsense mutations within alternatively spliced exons that lead to the production of normal levels of mRNA but result in the synthesis of truncated MHC protein(s) within certain muscles. We (O'Donnell and Bernstein 1988) and others (Dibb et al. 1985) have shown previously that many hypomorphic MHC alleles code for MHC proteins that lack carboxy-terminal amino acids and fail to accumulate as a result of their instability. Another possibility is that the $M h c^{9}$ and $M h c^{11}$ alleles are missense mutations that result in the production of full-length unstable proteins. If such mutations are within muscle-specific alternative exons, MHC instability would be restricted to 
the muscles whose transcripts contain the mutated coding region. Missense mutations in constitutive exons could also lead to muscle-specific MHC turnover. In this case, instability may result from the failure to interact with muscle-specific isoforms of other myofibrillar proteins. Molecular cloning and sequence analysis of these mutant alleles will resolve this matter.

\section{MHC isoform diversity and differential localization}

The variety of phenotypes seen in the homozygous-viable mutants $M h c^{7}$ and $M h c^{10}$ (and likely $M h c^{9}$ and $M h c^{11}$ ) provides genetic evidence that the alternatively spliced exons within the single MHC gene are processed in a highly specific fashion, resulting in the differential localization of MHC isoforms between individual muscles, within a single muscle, or even within a single cell. The phenotypes of the mutants suggest that the use of some alternatively spliced exons is muscle specific, whereas other exons are shared between the IFM, TDT, and perhaps additional muscles. For example, a domain that specifies a high ATPase activity may be unique to the IFM, where it is critical to generating high wing beat frequencies. In contrast, a domain that influences the assembly pattern of myosin molecules during the formation of the thick filament might be shared between the IFM and TDT because their filaments look very similar in cross section (for a discussion of myosin assembly patterns, see Squire 1981a,b). Thus, the effect of an alternative exon-specific mutation on muscle structure is dependent on the muscle-specific pattern of use of that exon.

Our observation of the differential effects of both the $M h c^{7}$ and $M h c^{9}$ mutations on the large and small cells of the TDT indicates that this muscle contains two fiber types. In Drosophila, the TDT is attached to the dorsal cuticle at one end and to the mesothoracic leg at the other end. The power required for jumping comes from the slow contraction of the muscle followed by its sudden release (Chapman 1982). The TDT also is essential for flight in some insects, although not in Drosophila (Crossley 1978; for a survey of the TDT muscle among the Diptera, see Smart 1956). Mixed fiber types have been described previously in insect muscles (Smit et al. 1967; Cochrane et al. 1972; Hoyle 1978). The different fiber types appear to work as antagonists in some of these instances; in other cases, they can be divided into tonic (fast) and phasic (slow) groups. Differences in mitochondrial area, abundance of sarcoplasmic reticulum and thick/thin filament ratios often differentiate the cell types. However, these parameters are similar for both cell types in the TDT of Drosophila. In fact, it was only because of the differential effects of the hypomorphic homozygous-viable mutations that the existence of the two cell types in the TDT was noticed. The individual contribution of each of the cell types to TDT function therefore is unclear.

The TDT small cell phenotype of $M h c^{7}$ and $M h c^{9}$ suggests that more than a single MHC isoform accumulates within these cells. The $M h c^{7}$ and $M h c^{9}$ mutations would only eliminate the production of isoforms using one par- ticular alternative exon, thus allowing some abnormal thick filaments to form. This phenotype is consistent with that seen in the muscles of $M h c^{1 /}+$ heterozygotes (O'Donnell and Bernstein 1988), where a reduced number of thick filaments and abnormally large-diameter thick filaments exist. This phenotype is also similar to that found in the body wall muscle of hypomorphic MHC mutants in C. elegans (Epstein et al. 1974; Waterston et al. 1980). In this muscle, two genes [MHC A and MHC B (or the unc-54 locus)], produce individual MHC isoforms that, together, assemble to form thick filaments (Garcea et al. 1978; Miller et al. 1983). unc-54 null mutants have a reduced number of thick filaments, suggesting that the MHC A isoform is capable of forming thick filaments in the absence of the MHC B isoform. Large-diameter thick filaments may result from overaccumulation of paramyosin relative to MHC, because similar abnormalities are observed in C. elegans unc-15 and unc-82 mutants (Waterston et al. 1980; Epstein et al. 1987). unc-15 encodes paramyosin and unc-82 appears to interact with paramyosin during thick filament formation (Waterston et al. 1980). The large-diameter thick filaments in these $C$. elegans mutants are composed mainly of paramyosin (Waterston et al. 1980; Epstein et al. 1987) and may be abnormal or nascent thick filament assemblages (Epstein et al. 1987).

Alternatively it is possible that multiple MHC isoforms do not accumulate within the small cells of the TDT. The reduced number of thick filaments could arise as a result of partial turnover of a single mutant MHC isoform. (The same isoform might be used in the IFM and the small cell of the TDT, but it would degrade more rapidly in the IFM as a result of this muscle's greater inherent sensitivity to the mutant protein.) Further analysis of the protein domain(s) defined by the $M h c^{7}$ and $M h c^{9}$ mutations with isoform-specific antibodies will determine whether multiple isoforms exist within single cells of the wild-type TDT and whether they are localized differentially within the myofibrils (Miller et al. 1983).

It is also possible that multiple MHC isoforms accumulate in leg muscles, on the basis of our observation that leg MHC levels in the $M h c^{10}$ strain are reduced partially. Leg muscles in this strain function adequately for locomotion, as these muscles possess relatively unorganized arrays of myofilaments whose arrangement and function are not severely affected by a $50 \%$ reduction in the overall number of thick filaments (Mogami et al. 1986; O'Donnell and Bernstein 1988). We have shown this to be true for all muscles except the IFM and TDT, which contain highly organized myofilament arrays that are critical to the more complex functions that they perform (O'Donnell and Bernstein 1988). The IFM and TDT myofibrillar arrays are altered dramatically when the thick filament number is reduced by $50 \%$. Thus, although the mutation $M h c^{10}$ affects MHC accumulation in legs and perhaps other muscles essential to viability, its effect in these muscles is not severe enough to result in lethality.

It is important to note that the homozygous-viable mutants described here may represent mutations in a 
Drosopbila myosin heavy-chain isofonn complexity

small subclass of the total number of Drosophila $\mathrm{MHC}$ isoforms. This is because only mutations that affect all isoforms of $\mathrm{MHC}$ (the homozygous-lethal class) or mutations in isoforms that accumulate in the IFM (the homozygous-viable class) were isolated when screening for dominant flightless mutants (Mogami and Hotta 1981). A number of isoforms specific to larval muscle or to other muscles of the adult may exist, and mutations in these isoforms would not be recovered as they do not affect flight muscle function. Because of their unique structures and fimctions, the IFM and TDT would be expected to accumulate MHC isoforms not shared with other Drosophila muscles. We described three distinct mutant phenotypes that have the same effect on the IFM but different effects on the TDT, suggesting that the overall MHC isoform distribution in Drosophila muscles will be very complex.

The analysis of MHC isoform distribution in Drosophila should prove invaluable in attempting to understand the contribution of MHC diversity to the assembly of muscles capable of performing unique functions. Such analyses have proved difficult in vertebrates because $\mathrm{MHC}$ heterogeneity is encoded by large gene families. A major goal of future research will be to define the tissue-specific use of particular exons of the Drosophila MHC gene. Determining the molecular lesions responsible for the phenotypes seen in the homozygous-viable class of MHC mutants and in situ hybridization with exon-specific probes should prove valuable in this regard. Analysis of the mutants is significant in that it will allow us to correlate the failure to express a particular MHC isoform with structural aberrations in particular muscles. The homozygous-viable mutants also should prove to be a valuable tool in our attempt to define the functions of the domains of the $\mathrm{MHC}$ protein encoded by the alternatively spliced exons. The null phenotypes of the mutants make them ideal recipients for germ-line transformation with $\mathrm{MHC}$ gene constructs containing a single member of a particular alternatively spliced exon set that normally is not expressed in the IFM. These experiments will force the IFM to use an alternative exon normally associated with other muscles. The IFM of the transformant would likely exhibit novel biochemical or structural properties, thus defining a function for the MHC domain encoded by the particular set of alternatively spliced exons being analyzed.

\section{Materials and methods}

\section{Materials}

Paraformaldehyde, glutaraldehyde. Spurt's embedding medium, uranyl acetate, and lead citrate were from Ted Pella (Irvine, California). The diamond knife was from EM Corporation (Chestnut Hill, Massachusetts). Cryosections were cut on a cryostat (Harris Manufacturing Co., Billerica, Massachusetts). O.C.T. embedding compound was from Labtek Division, Miles Laboratory (Elkhart, Indiana). Polymount was from American Scientific Products (McGaw Park, Illinois). NTB-2 emulsion was from Kodak (Rochester, New York). MS-Labeled UTP was from Amersham (Arlington Heights, Illinois). Most reagent grade molecular biology reagents were from Bethesda Research Laboratories (Gaithersburg, Maryland).
Methods

Mapping and nomenclature of the homozygous-viable mutants $M h c^{\wedge}, M h c^{\wedge}, M h c^{\wedge}$, and $M h c^{\wedge \wedge}$ were mapped relative to the MHC mutation $M h c^{\wedge}$ in the following maimer. Progeny of the cross between $b M h d \mathrm{pr} /$ mutant females and homozygous al b pr px sp males were examined and scored for the number of recombinant fliers and the number of recombinants between $b$ and $p r$. Morphological marker genes were aristaless (2-0.01), black (2-48.5), purple (2-54.5), plexus (2-100.5), and speck $(2-107.0) . M h c^{\wedge}$ is dominant-flightless and homozygous-lethal MHC mutation (Mogami et al. 1986) and has been shown to be a small deletion within the $\mathrm{MHC}$ gene (O'Donnell and Bernstein 1988). Phenotypes of the other markers are given in Lindsley and Grell (1968). MHC mutations are named as follows: $M h c^{\wedge}-M h c^{\wedge}$ are recessive lethals (Mogami et al. 1986); $M h c^{\wedge}=B s h$ (see Lindsley and Grell 1968); $M h c^{\wedge}=\operatorname{Ifm}(2) l$ [Homyk and Emerson (1988) tentatively have assigned Bsh and Ifm(2)l as MHC mutations); $M h c^{\wedge}=\operatorname{Ifm}(2) 2 ; M h c^{\wedge}=\operatorname{Ifm}(2) 3$ (see Mogami and Hotta 1981); $M h c^{\wedge}$ and the new alleles $M h c^{\wedge}$, $M h c^{\wedge \circ}$, and Mijc" are the homozygous-viable mutants discussed in this communication. This nomenclature scheme was kindly suggested by D.L. Lindsley and G. Zimm.

Genetic rescue of the flightless phenotypes with a MHC duplication The stock Ki Dp(2-3) osp3/TM3 (Simpson 1983, provided by T. Homyk and T.R.F. Wright) has a portion of the second chromosome $(35 \mathrm{~B} 3,4-36 \mathrm{C} 11)$ containing the MHC gene (at $36 \mathrm{~B}$ ) transposed to the $98 \mathrm{E}, \mathrm{F}$ region of chromosome 3 . This duplication stock contains a dominant bristle marker $\{\mathrm{Ki}$ ) on the mutated third chromosome that allows one to follow the inheritance of the duplication in progeny. Males from this duplication stock were crossed to homozygous flightless mutant virgins, and the progeny possessing the dominant marker (Ali3C" $/ \mathrm{Mic}+/$ mutation) were tested for flight ability.

Measurement of TDT function Homozygous mutants from each strain (or wild-type flies that had had their wings clipped) were shaken onto an inverted petri dish raised $4 \mathrm{~cm}$ over a motor oil-coated piece of styrofoam on which a circle equal to the diameter of the petri dish had been drawn. As flies jumped (or fell) into the oil, they died almost instantly. The positions of 30 flies of each strain relative to the edge of the circle were measured, and an average value was calculated. $M h c^{\wedge \circ}$ flies exhibit no vertical jumping ability; therefore, their average distance from the edge of the circle was subtracted from the average distance of each of the strains, giving $M h c^{\wedge \circ}$ a value of $0 \%$ for its relative jump muscle function. The corrected wildtype flies' value was considered to indicate $100 \%$ jump muscle function. Jump muscle function of the other mutants then was calculated relative to the corrected wild-type value.

Protein analysis of the homozygous-viable mutants To examine MHC protein accumulation in the thoraces of homozygous mutant and Canton $\mathrm{S}$ (wild-type) organisms, the upper thoraces of six adult females, containing a portion of the IFM and TDT, were homogenized in 70 il of SDS-sample loading buffer (Laemmli 1970). After boiling, $35 \mathrm{kl}$ of the final volume was loaded onto a polyacrylamide gel containing SDS (Laemmli 1970). Leg MHC protein accumulation was examined by homogenizing the legs of six adult females in $45 \mathrm{MH}$ of SDSsample buffer, after boiling, the entire sample was loaded onto a polyacrylamide gel. Following electrophoresis, the gels were stained with Coomassie Brilliant blue and the lanes were scanned with a laser densitometer. MHC accumulation in mutants then was compared to accumulation in the wild type. To 
correct for variations in amount of protein loaded, the observed MHC content was divided by the value obtained for two major thoracic proteins $\left(M_{x} 45,000\right.$ and 53,000$)$ or a single leg protein $\left(M_{r} 45,000\right)$. (The $45 \mathrm{kD}$ protein is actin.) Accumulation of these proteins is not affected by the mutations (data not shown). MHC content then was calculated as a percentage of wild-type levels. Analysis of proteins by two-dimensional electrophoresis was as described previously (Mogami and Hotta 1981).

Electron microscopy of muscles Samples were prepared for electron microscopy as described by O'Donnell and Bernstein (1988).

\section{In situ hybridization}

Preparation of tissue cryosections In situ hybridization was performed on late-stage pupae in which red eye pigment and dark wings were clearly visible ( $\sim 24 \mathrm{hr}$ pre-eclosion). Cryosections were prepared by placing a single pupa in a large drop of O.C.T. embedding medium contained on a specimen stage. The specimen stage then was inverted and frozen quickly in liquid nitrogen. Sections $(8 \mu \mathrm{m})$ were cut on a cryostat. Sections were picked up on subbed slides ( $0.5 \%$ gelatin, $0.05 \%$ chrome alum). Slides with sections were heated on a hot plate at $55^{\circ} \mathrm{C}$ for 2 min and placed at $4^{\circ} \mathrm{C}$ until all sectioning was complete. Sections then were fixed in $4 \%$ paraformaldehyde in $1 \times$ PBS buffer $\left(10 \times \mathrm{PBS}\right.$ is $1.3 \mathrm{M} \mathrm{NaCl}, 0.07 \mathrm{M} \mathrm{Na}_{2} \mathrm{HPO}_{4}, 0.03 \mathrm{M} \mathrm{NaH}_{2} \mathrm{PO}_{4}$ ) for $20 \mathrm{~min}, 3 \times$ PBS buffer for $5 \mathrm{~min}$, and $1 \times$ PBS buffer for $5 \mathrm{~min}$ and dehydrated through an ethanol series (Hafen and Levine 1986). To increase efficiency of hybridization, this was followed by treatment with $1 \mu \mathrm{g} / \mathrm{ml}$ proteinase $\mathrm{K}$ in $0.1 \mathrm{M}$ Tris- $\mathrm{HCl}$ and $50 \mathrm{~mm}$ EDTA ( $\mathrm{pH} 7.5$ ) for $30 \mathrm{~min}$ at room temperature (Cox et al. 1984). Slides then were placed in a solution of $2 \mathrm{mg} / \mathrm{ml} \mathrm{gly-}$ cine for $30 \mathrm{sec}$, followed by $0.2 \mathrm{M} \mathrm{HCl}$ for $20 \mathrm{~min}$. Sections were fixed in $4 \%$ paraformaldehyde in $1 \times$ PBS buffer for $20 \mathrm{~min}, 3 \times$ PBS buffer for $5 \mathrm{~min}$, and $1 \times$ PBS buffer for $5 \mathrm{~min}$ and dehydrated in an ethanol series.

Preparation of radioactively labeled $R N A$ probes An $X b a \mathrm{I}-$ $X m n I$ restriction fragment containing constitutive exons 4, 5, and 6 of the Drosophila muscle MHC gene (Wassenberg et al. 1987; O'Donnell and Bernstein 1988) cloned adjacent to the SP6 promoter (of vector pSP64) was used in conjunction with SP6 RNA polymerase to generate an antisense RNA probe that hybridizes to all transcripts of the MHC gene. In addition, a SalI$X b a$ I fragment containing exons 4,5 , and 6 cloned next to the T3 promoter (of vector $\mathrm{pKS}$ ) was used in conjunction with $\mathrm{T} 3$ RNA polymerase to generate a sense RNA probe that should not hybridize to any transcripts from the MHC gene. ${ }^{35} \mathrm{~S}-\mathrm{La}$ beled UTP $(800 \mathrm{Ci} / \mathrm{mmole})$ was the only radioactively labeled nucleotide present in transcript labeling reactions designed to produce probes with high specific activity (Melton et al. 1984, as modified in the 1985/1986 Promega Biotec Catalog). The transcription reactions were terminated by digesting with 1 unit DNase (RNase-free) per microgram template for $20 \mathrm{~min}$ at $37^{\circ} \mathrm{C}$. The samples then were phenol/chloroform extracted, chloroform extracted, and precipitated by adding $25 \mu \mathrm{g}$ tRNA, one-tenth volume of $3 \mathrm{M} \mathrm{Na}$ acetate $(\mathrm{pH} 6.0)$, and 2.5 volumes of ethanol. RNAs were resuspended in $50 \mu \mathrm{l}$ of water and size reduced by alkaline hydrolysis by adding 6 volumes of $40 \mathrm{mM}$ $\mathrm{NaHCO}_{3}, 60 \mathrm{mM} \mathrm{Na}_{2} \mathrm{CO}_{3}$ (pH 10.2) and incubating at $60^{\circ} \mathrm{C}$. The time of hydrolysis was determined as described by Cox et al. (1984). Following alkaline hydrolysis the samples were neutralized by adding glacial acetic acid $[0.5 \%(\mathrm{vol} / \mathrm{vol})$ and one-tenth volume of $3 \mathrm{M} \mathrm{Na}$ acetate $[\mathrm{pH} 6.0)]$. The RNAs then were precipitated by adding 2.5 volumes of ethanol. Following centrifugation, the RNAs were washed in $70 \%$ ethanol, dried in vacuo, and resuspended in hybridization buffer $[50 \%$ formamide, $0.3 \mathrm{M}$ $\mathrm{NaCl}, 20 \mathrm{~mm}$ Tris-HCl (pH 8.0), $5 \mathrm{~mm}$ EDTA, $1 \times$ Denhardt's solution, $500 \mu \mathrm{g}$ of yeast tRNA/ml, 10\% dextran sulfate] to concentrations of $0.3 \mu \mathrm{g} / \mathrm{ml}$ (Melton 1984, as outlined in the 1985/1986 Promega Biotec Catalog).

Hybridization of tissue sections Hybridization probes were incubated at $80^{\circ} \mathrm{C}$ for $15 \mathrm{~min}$ and cooled quickly on ice. Twenty-five microliters of probe was placed on each of the slides, which were then covered by $24 \times 50-\mathrm{mm}$ coverslips. To prevent evaporation, the edges of the coverslips were sealed with rubber cement and the slides were placed in a moist chamber. Hybridization was performed in an incubator overnight at $50^{\circ} \mathrm{C}$. The rubber cement then was stripped gently from each of the slides using a pair of forceps and the coverslips were removed by dipping the slides in a solution of $4 \times \operatorname{SSC~}(\mathrm{pH} 7.0)$ $(20 \times \mathrm{SSC}$ is $3 \mathrm{M} \mathrm{NaCl}, 0.3 \mathrm{M} \mathrm{Na}$ citrate). The slides were treated with $20 \mu \mathrm{g} / \mathrm{ml}$ of RNase A and washed as described by Cox et al. (1984).

Autoradiography Under safe light conditions, the dry slides were dipped in Kodak NTB-2 emulsion /diluted 1:1 with water) and allowed to dry vertically for $30 \mathrm{~min}$ on a paper towel. Slides then were incubated in a light-tight box that contained $\mathrm{CaSO}_{4}$ drying agent at $4^{\circ} \mathrm{C}$. Slides were allowed to expose for 3-4 days and then were processed by placing in Kodak D-19 developer for $2.5 \mathrm{~min}$, washing in water for $30 \mathrm{sec}$ and treating with Kodak fixer for $5 \mathrm{~min}$ (all solutions were precooled to $15^{\circ} \mathrm{C}$. Slides were washed gently for $15 \mathrm{~min}$ in water at room temperature and then stained with $5 \%$ Giemsa for $20 \mathrm{sec}$. Slides were rinsed, air-dried, and mounted with coverslips using Polymount medium. Sections were examined with bright-field microscopy and photographed using Kodak Ektachrome 50 tungsten color slide film.

\section{Acknowledgments}

We thank William Kronert for his excellent technical assistance with the electron microscopy of the mutants and Donald Wassenberg and Dianne Hodges for making the MHC transcription constructs. We thank Scott Falkenthal for helpful discussions. We are indebted to Dianne Hodges, David Becker, and Norbert Hess for their critical suggestions concerning the manuscript. This work was supported by research grants to S.I.B. from the National Institutes of Health (GM-32443) and the Muscular Dystrophy Association and a grant-in-aid for General Scientific Research to K. M. from the Japan Ministry of Education, Science, and Culture.

\section{References}

Bernstein, S.I., K. Mogami, J.J. Donady, and C.P. Emerson Jr. 1983. Drosophila muscle myosin heavy chain encoded by a single gene in a cluster of muscle mutations. Nature 302: 393-397.

Bernstein, S.I., C.J. Hansen, K.D. Becker, D.R. Wassenberg II, E.S. Roche, J.J. Donady, and C.P. Emerson Jr. 1986. Alternative RNA splicing generates transcripts encoding a thoraxspecific isoform of Drosophila melanogaster myosin heavy chain. Mol. Cell. Biol. 6: 2511-2519. 
Chapman, R.F. 1982. Locomotion. In The insects, structure and function, pp. 169-196. Harvard University Press, Cambridge, Massachusetts.

Chun, M. and S. Falkenthal. 1988. Ifm(2)2 is a myosin heavy chain allele that disrupts myofibrillar assembly only in the indirect flight muscle of Drosophila melanogaster. $J$. Cell Biol. 107: 2613-2621.

Cochrane, D.G., H.Y. Elder, and P.N.R. Usherwood. 1972. Physiology and ultrastructure of phasic and tonic skeletal muscle fibres in the locust, Schistocerca Gregaria. I Cell. Sci. 10: 419-441.

Cox, K.H., D.V. DeLeon, L.M. Angerer, and R.C. Angerer. 1984. Detection of mRNAs in sea urchin embryos by in situ hybridization using asymmetric RNA probes. Dev. Biol. 101: 485-502.

Crossley, A.C. 1978. The morphology and development of the Drosophila muscular system. In The genetics and biology of Drosophila. (ed. M. Ashburner and T.R.F. Wright), vol. 2b, pp. 499-560. Academic Press, London.

Cullen, M.J. 1974. The distribution of asynchronous muscle in insects with particular reference to the Hemiptera: An electron microscopy study. I. Entomol. 49: 17-41.

Deak, I.I. 1977. Mutations of Drosophila melanogaster that affect muscles. I. Embryol. Exp. Morphol. 40: 35-63.

Dibb, N.J., D.M. Brown, J. Karn, D.G. Moerman, S.L. Bolten, and R.H. Waterston. 1985. Sequence analysis of mutations that affect the synthesis, assembly and enzymatic activity of the unc-54 myosin heavy chain of Caenorhabditis elegans. J. Mol. Biol. 183: 543-551.

Emerson, C.P., Jr. and S.I. Bernstein. 1987. Molecular genetics of myosin. Annu. Rev. Biochem. 56: 695-726.

Epstein, H.F., I. Ortiz, and G.C. Berliner. 1987. Assemblages of multiple thick filaments in nematode mutants. $J$. Muscle Res. Cell Motility 8: 527-536.

Epstein, H.F., R.H. Waterston, and S. Brenner. 1974. A mutant affecting the heavy chain of myosin in Caenorhabditis elegans. J. Mol. Biol. 90: 291-300.

Garamvolgyi, N. 1965a. The arrangement of the myofilaments in the insect flight muscle. I. J. Ultrastruct. Res. 13: 409424.

-1965b. The arrangement of the myofilaments in the insect flight muscle. II. J. Ultrastruct. Res. 13: 425-434.

Garcea, R.C., F. Schachat, and H.F. Epstein. 1978. Coordinate synthesis of two myosins in wild-type and mutant nematode muscle during larval development. Cell 15: 421-428.

George, E., M. Ober, and C.P. Emerson Jr. 1989. Functional domains of the Drosophila melanogaster muscle myosin heavy chain gene are encoded by alternatively spliced exons. Mol. Cell. Biol. 9: 2957-2974.

Hafen, E. and M. Levine. 1986. The localization of RNAs in Drosophila tissue sections by in situ hybridization. In Drosophila, a practical approach. (ed. D.B. Roberts), pp. 139-158. IRL Press, Washington DC.

Hess, N., W.A. Kronert, and S.I. Bernstein. 1989. Transcriptional and post-transcriptional regulation of Drosophila myosin heavy chain gene expression. In Cellular and molecular biology of muscle development. (ed. L.H. Kedes and F.E. Stockdale), pp. 621-631. A.R. Liss, New York.

Hiromi, Y. and Y. Hotta. 1985. Actin gene mutations in Drosophila; heat shock activation in the indirect flight muscles. EMBO J. 4: 1681-1687.

Homyk, T., Jr. and C.P. Emerson Jr. 1988. Functional interactions between unlinked muscle genes within haploinsufficient regions of the Drosophila genome. Genetics 119: 105121.

Hoyle, G. 1978. Distribution of nerve and muscle fibre types in locust jumping muscle. I. Exp. Biol. 73: 205-223.

Karlik, C.C. and E.A. Fyrberg. 1985. An insertion within a variably spliced Drosophila tropomyosin gene blocks the accumulation of only one encoded isoform. Cell 41: 57-66.

Karlik, C.C., M.D. Coutu, and E.A. Fyrberg. 1984. A nonsense mutation within the Act $88 \mathrm{~F}$ actin gene disrupts myofibril formation in Drosophila indirect flight muscles. Cell 38: 711-719.

Karn, J., S. Brenner, and L. Barnett. 1983. Protein structural domains in the Caenorhabditis elegans unc-54 myosin heavy chain gene are not separated by introns. Proc. Natl. Acad. Sci. 80: 4253-4257.

Kidd, S., T.J. Lockett, and M.W. Young. 1983. The Notch locus of Drosophila melanogaster. Cell 34: 421-433.

Kiehart, D.P. and T.D. Pollard. 1984. Stimulation of Acanthamoeba actomyosin ATPase activity by myosin-II polymerization. Nature 308: 864-866.

Kiehart, D.P., D.A. Kaiser, and T.D. Pollard. 1984. Direct localization of monoclonal antibody-binding sites on Acanthamoeba myosin-II and inhibition of filament formation by antibodies that bind to specific sites on the myosin-II tail. $J$. Cell. Biol. 99: 1015-1023.

Koana, T. and Y. Hotta. 1978. Isolation and characterization of flightless mutants in Drosophila melanogaster. J. Embryol. Exp. Morphol. 45: 123-143.

Kuczmarski, E.R. and J.A. Spudich. 1980. Regulation of myosin self-assembly: Phosphorylation of Dictyostelium heavy chain subunits inhibits formation of thick filaments. Proc. Natl. Acad. Sci. 77: 7292-7296.

Laemmli, U.K. 1970. Cleavage of structural proteins during the assembly of the head of bacteriophage T4. Nature 227: 680685.

Lindsley, D.L. and E.H. Grell. 1968. Genetic variation of Drosophila melanogaster. Carnegie Inst. Wash. Publ. 627.

Mahdavi, V., A.P. Chambers, and B. Nadal-Ginard. 1984. Cardiac alpha and beta-myosin heavy chain genes are organized in tandem. Proc. Natl. Acad. Sci. 81: 2626-2630.

Mahdavi, V., M. Periasamy, and B. Nadal-Ginard. 1982. Molecular characterization of two myosin heavy chain genes expressed in the adult heart. Nature 297: 659-664.

Melton, D.A., P.A. Krieg, M.R. Rebagliati, T. Maniatis, K. Zinn, and M.R. Green. 1984. Efficient in vitro synthesis of biologically active RNA and RNA hybridization probes from plasmids containing a bacteriophage SP6 promoter. Nucleic Acids Res. 12: 7035-7056.

Miller, A. 1950. The internal anatomy and histology of the imago of Drosophila melanogaster. In The biology of Drosophila (ed. M. Demerec), pp. 468-480. John Wiley and Sons, New York.

Miller, D.M., I. Ortiz, G.C. Berliner, and H.F. Epstein. 1983. Differential localization of two myosins within nematode thick filaments. Cell 34: 477-490.

Mogami, K. and Y. Hotta. 1981. Isolation of Drosophila flightless mutants which affect myofibrillar proteins of indirect flight muscle. Mol. Gen. Genet. 183: 409-417.

Mogami, K., P.T. O'Donnell, S.I. Bernstein, T.R.F. Wright, and C.P. Emerson Jr. 1986. Mutations of the Drosophila myosin heavy-chain gene: Effects on transcription, myosin accumulation, and muscle function. Proc. Natl. Acad. Sci. 83: 1393-1397.

Nachtigall, W. and D.M. Wilson. 1967. Neuromuscular control of Dipteran flight. J. Exp. Biol. 47: 77-97.

O'Donnell, P.T. and S.I. Bernstein. 1988. Molecular and ultrastructural defects in a Drosophila myosin heavy chain mutant: Differential effects on muscle function produced by similar thick filament abnormalities. J. Cell. Biol. 


\section{O'Donnell et al.}

107: 2601-2612.

Peristianis, G.C. and D.W. Gregory. 1970. Early stages of flight muscle development in the blowfly Lucilia Cuprina: A light and electron microscopy study. /. Insect Physiol. 17: 10051022 .

Pringle, J.W.S. 1967. The contractile mechanism of insect fibrillar muscle. Prog. Biophys. Mol. Biol. 17: 1-60.

Rozek, C.E. and N. Davidson. 1983. Diosophila has one myosin heavy chain gene with three developmentally regulated transcripts. Cell 32: 23-34.

1986. Differential processing of RNA transcribed from the single-copy Diosophila myosin heavy chain gene produces four mRNAs that encode two polypeptides. Pioc. Natl. Acad. Aci. 83:2128-2132.

Shafiq, S.A. 1963a. Electron microscopic studies on the indirect flight muscles of Diosophila melanogastei. I. Structure of the myofibrils. /. Cell Biol. 17: 351-362.

1963b. Electron microscopic studies on the indirect flight muscles of Diosophila melanogastei. II. Differentiation of the myofibrils. /. Cell Biol. 17:363-373.

Silberstein, L., S.G. Webster, M. Travis, and H.M. Blau. 1986. Developmental progression of myosin gene expression in cultured muscle cells. Cell 46: 1075-1081.

Simpson, P. 1983. Matemal-zygotic gene interactions during formation of the dorsoventral pattern in Diosophila embryos. Genetics 105: 615-632.

Smart, J. 1956. The tergal depressor of the trochanter muscle in Diptera. Pioc. Tenth Int. Congiess Entomol. 1: 551-555.

Smit, W.A., G. Becht, and A.M. Beenakkers. 1967. Structure, fatigue and enzyme activities in 'fast' insect muscles. Insect Physiol. 13: 1857-1868.

Smith, D.S. 1963. The structure of flight muscle sarcosomes in the blowfly Calliphora erythrocephala. /. Cell Biol. 19: $115-$ 138.

Squire, J. 1981a. Comparative ultrastructures of diverse muscle types. In The stiuctuial basis of muscle contiaction, pp. 381-469. Plenum Press, New York.

1981b. Molecular packing in myosin-containing filaments. In The stiuctuial basis of muscle contiaction, pp. 471-522. Plenum Press, New York

Swynghedauw, B. 1986. Developmental and functional adaptation of contractile proteins in cardiac and skeletal muscles. Physiol. Rev. 66: 710-771.

Thorson, J. and D.C.S. White. 1969. Distributed representations for actin-myosin interaction in the oscillatory contraction of muscle. Biophys. J. 9: 360-390.

Tregear, R.T. 1975. The biophysics of fibrillar flight muscle. In Insect muscle, (ed. P.N.R. Usherwood), pp. 357-403. Academic Press, New York.

Umeda, P.K., C.J. Kavinsky, A.M. Sinha, H.J. Hsu, S. Jakovcic, and M. Rabinowitz. 1983. Cloned mRNA sequences for two types of embryonic myosin heavy chains from chick skeletal muscle. . Biol. Chem. 258: 5206-5214.

Wassenberg II, D.R., W.A. Kronert, P.T. O'Donnell, and S.I. Bernstein. 1987. Analysis of the $5^{\prime}$ end of the Diosophila muscle myosin heavy chain gene: Alternatively spliced transcripts initiate at a single site and intron locations are conserved compared to myosin genes of other organisms. /. Biol. Chem. 262: 10741-10747.

Waterston, R.H., J.N. Thomson, and S. Brenner. 1980. Mutants with altered muscle structure in Caenoihabditis elegans. Dev.Biol. 77:271-302.

Whalen, R.E., S. Sell, G.S. Butler-Browne, K. Schwartz, P. Bouveret, and I. Pinset-Harstrom. 1981. Three myosin heavychain isozymes appear sequentially in rat development. $\mathrm{Na}$ tuie 292: 805-809. 


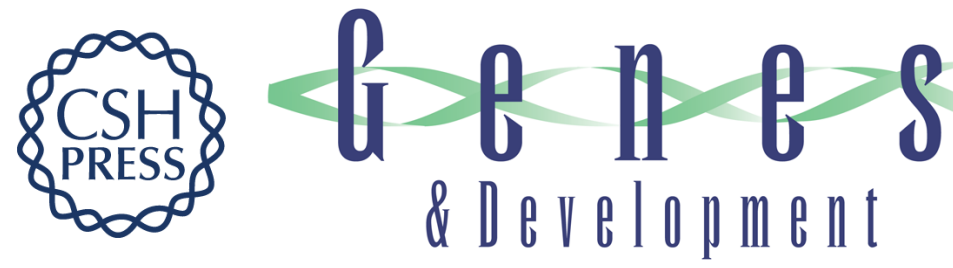

\section{Ultrastructural and molecular analyses of homozygous-viable Drosophila melanogaster muscle mutants indicate there is a complex pattern of myosin heavy-chain isoform distribution.}

P T O'Donnell, V L Collier, K Mogami, et al.

Genes Dev. 1989, 3:

Access the most recent version at doi:10.1101/gad.3.8.1233

References This article cites 52 articles, 18 of which can be accessed free at: http://genesdev.cshlp.org/content/3/8/1233.full.html\#ref-list-1

License

Email Alerting Service

Receive free email alerts when new articles cite this article - sign up in the box at the top right corner of the article or click here.

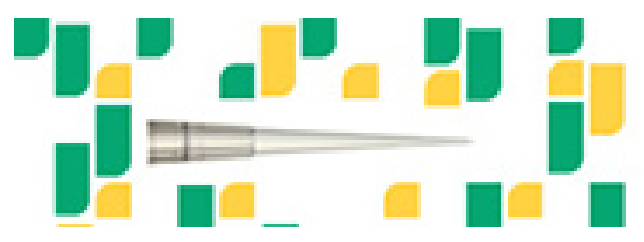

Focused on your science. 